\title{
Laryngeal nerve identification during thyroid surgery - feasibility of a novel approach
}

[L'identification du nerf laryngé pendant l'opération de la thyroïde - la faisabilité d'une nouvelle approche]

Carl L. Hillermann FrCA, ${ }^{*}$ Joe Tarpey FfarCsI, ${ }^{*}$ David E. Phillips FCs $†$

Purpose: Recurrent laryngeal nerve damage remains one of the most devastating complications of thyroid surgery. However, nerve identification is not always easy, and a reliable method to locate nerves intraoperatively is needed.

Methods: Thirty consecutive patients were anesthetized for elective thyroid surgery using a standard technique. Indications for surgery covered a broad spectrum of conditions. In the technique described, the airway is secured with a micro laryngeal tube, and a laryngeal mask airway is inserted through which a fibreoptic scope is inserted to view the larynx. Movement of the arytenoids in response to nerve stimulation can be viewed at any time on a television monitor. The airway is secure throughout the procedure and nerve identification is continuously available.

Results: In our study 30 patients were anesthetized and nerve stimulation used in all of them to identify both superior and recurrent laryngeal nerve. None of them developed intraoperative complications. One patient had temporary postoperative recurrent laryngeal nerve damage, which was not attributable to use of this method.

Conclusion: On the basis of our results so far, the method described is feasible and provides a safe method of nerve location during surgery. Laryngeal nerve stimulation is likely to become an integral part of thyroid surgery.

Objectif : Les dommages du nerf laryngé récurrent demeurent la complication la plus dévastatrice de l'opération de la thyroïde. Cependant, l'identification du nerf n'est pas toujours facile et il faut trouver une méthode de détection peropératoire fiable.

Méthode : Trente patients successifs ont été anesthésiés pour une opération planifiée de la thyroïde selon une technique normalisée. Selon la technique utilisée, les voies aériennes sont protégées par une microsonde laryngée et un masque laryngé est inséré. Une sonde fibroscopique est aussi insérée, au travers du masque, pour visualiser le larynx. Des mouvements des cartilages aryténoïdes, en réponse à une stimulation nerveuse, peuvent être visualisés en permanence à l'écran et l'identification du nerf est toujours possible, car la perméabilité des voies aériennes est maintenue pendant toute l'opération.

Résultats : La stimulation nerveuse a été utilisée chez les 30 patients anesthésiés de notre étude afin d'identifier les nerfs laryngé supérieur et récurrent. Aucune complication peropératoire n'est survenue. Un patient a subi un dommage postopératoire temporaire du nerf laryngé récurrent, non attribué à notre méthode d'identification.

Conclusion : D'après les résultats obtenus jusqu'à maintenant, la méthode décrite est faisable et permet une identification peropératoire du nerf sans danger. La stimulation du nerf laryngé pourrait donc être intégrée à l'opération de la thyroïde.

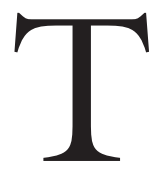

HYROIDECTOMIES continue to produce complications with the most devastating being damage to the recurrent laryngeal nerve. ${ }^{1}$ The rate of recurrent laryngeal nerve palsy varies from $2 \%$ to $17 \%$ and for superior laryngeal nerve from $9 \%$ to $14 \%{ }^{2}$ Trauma to one of the laryngeal nerves is more likely if there are variations or distortions of anatomy, malignancy, previous radiation or revision surgery.

It is standard practice to identify the recurrent laryngeal nerve but this is not always possible. A recent study identifies failure to find the nerve in as many as $18 \%$ of cases. ${ }^{3}$ Mountain et al. showed that the incidence of nerve paralysis was three to four times greater in cases where the nerve was not exposed than in cases where it was routinely exposed. ${ }^{4}$

From the Department of Anaesthesia, ${ }^{*}$ and the Department of Surgery, $\dagger$ Warwick Hospital, Warwick, United Kingdom. Address correspondence to: Dr. Carl L. Hillermann, Department of Anaesthesia, Faculty of Medicine, University of Natal, Private Bag 7 , Congella, 4103 South Africa. Phone: +27 31 2604328/9; Email: chillermann@yahoo.co.uk

Preliminary finding presented at the 9th annual meeting of the European Society of Anaesthesiologists in Gothenburg, Sweden in April 2001. Accepted for publication June 17, 2002.

Revision accepted November 6, 2002. 
A surgical technique that would help in locating the recurrent laryngeal and superior laryngeal nerve during surgery could potentially reduce damage to these nerves. Electrical stimulation of the facial nerve during skull base and parotid surgery is employed by many surgeons to identify the trunk and path of the nerve. On stimulation facial movements are readily seen.

A similar approach has been advocated during thyroidectomy with a fibreoptic scope and laryngeal mask airway (LMA) to visualize the vocal cords following electrical stimulation of the laryngeal nerves. ${ }^{5-9}$ However, all these have reported an incidence of loss of airway control intraoperatively, which could have catastrophic consequences to the patient. Furthermore, correction of the airway during the procedure may be difficult owing to the very nature of head and neck surgery.

Our aims in developing the technique were:

To secure the airway throughout the procedure, thus ensuring the patient was not put at risk.

To facilitate location of the recurrent and superior laryngeal nerve during surgery, thereby reducing risk of nerve damage.

To confirm nerve integrity prior to the completion of surgery.

\section{Method}

Thirty consecutive patients (ASA I-III) with an age range of 30-79 yr (mean age $59 \mathrm{yr}$ ) were anesthetized for elective thyroid surgery. All patients had their vocal cord function assessed preoperatively by an otorhinolaryngologist (DEP) using a nasal endoscope. As the technique is suitable for all patients there were no exclusions from this series. A standard pre-medication of ranitidine $150 \mathrm{mg}$, metoclopramide $10 \mathrm{mg}$ and temazepam 20-30 mg was administered 90 min prior to surgery. Intravenous access was obtained and monitoring was implemented as recommended by the Association of Anaesthetists of Great Britain and Ireland. After preoxygenation the patients had a standard induction with propofol $1.5-2.5 \mathrm{mg} \cdot \mathrm{kg}^{-1}$, fentanyl $1.5 \mu \cdot \mathrm{kg}^{-1}$ and vecuronium $0.1 \mathrm{mg} \cdot \mathrm{kg}^{-1}$. Laryngoscopy was performed using a Macintosh blade and the patient was intubated using a size 5.0 micro laryngeal tube (MLT), which was placed centrally or, in patients for hemi-thyroid surgery, on the side contra-lateral to the surgical site. The MLT was inflated using air until a seal was achieved. Ventilation of the lungs was instituted via a circle system and a Carden ventilator (Mie, Exeter, United Kingdom). Maintenance of anesthesia was with oxygen, nitrous oxide $66 \%$ and isoflurane. End-tidal carbon dioxide was kept at 3.5-4.0 kPa to diminish the respiratory drive. No repeat doses of vecuronium were required after induction. The patient was then posi- tioned for thyroid surgery with a sandbag placed under the shoulders and a head ring positioned with the head extended.

Once in position, a LMA (size 3-4) was placed posterior to the MLT and partially inflated with $10-15 \mathrm{~mL}$ of air. This was used as a conduit for easy and reliable placement of a fibreoptic nasendoscope (Olympus ENF P3, Olympus-Optical, Japan). The fibreoptic scope attached to a television monitor was then used to view the larynx. The arytenoids on the side of surgery had to be fully visible and unhindered by the LMA and MLT before the view was accepted. If the view was poor, adjustments were made to either the LMA or the MLT, or a different size LMA was used.

The patient was then draped to allow access to the LMA throughout the case so that adjustments to the fibreoptic scope could be made (Figure). Surgery then commenced and at intervals the surgeon used a nerve stimulator (Anaestim 2, Viamed, Keighley, West Yorkshire, United Kingdom) to assist in locating and tracing the recurrent and superior laryngeal nerves. An insulated 20G needle (Braun, Melsungen AG, Germany) was used and the stimulator was set to deliver a $0.5 \mathrm{~mA}$ pulse at a frequency of $0.5 \mathrm{~Hz}$. During stimulation the movement of the arytenoids was observed on the monitor. The use of vecuronium did not hinder movement of the vocal cords, as the time from induction to nerve stimulation was greater than $40 \mathrm{~min}$. In no case was residual block an issue.

This process was repeated as necessary throughout the surgery to confirm the position of the nerve and its function. At the end of surgery, nerve function was confirmed and the neck closed. Spontaneous respiration was re-established and the patient extubated under deep anesthesia with the laryngeal mask being used as an airway in the recovery period.

\section{Results}

Indications for surgery in this series covered a broad spectrum of conditions (Table). None of our patients developed problems associated with airway control intraoperatively or during the postoperative period. Thus no anesthetic airway intervention was required peroperatively.

Electrical nerve stimulation was used in all 30 patients to trace both the superior and recurrent laryngeal nerves during surgery. Of these 30 patients only one developed a temporary postoperative recurrent laryngeal nerve palsy, and this fully recovered within six months. In this case surgery was particularly difficult due to thyroiditis. However the surgeon found the ability to trace the nerve to be of great benefit in preventing further damage. 
TABLE Indications for surgery

\begin{tabular}{ll}
\hline Multinodular goitre & 15 \\
Papillary carcinoma & 6 \\
Hürtel cell carcinoma & 1 \\
Hashimotos thyroiditis & 4 \\
Follicular adenomata & 4 \\
\hline
\end{tabular}

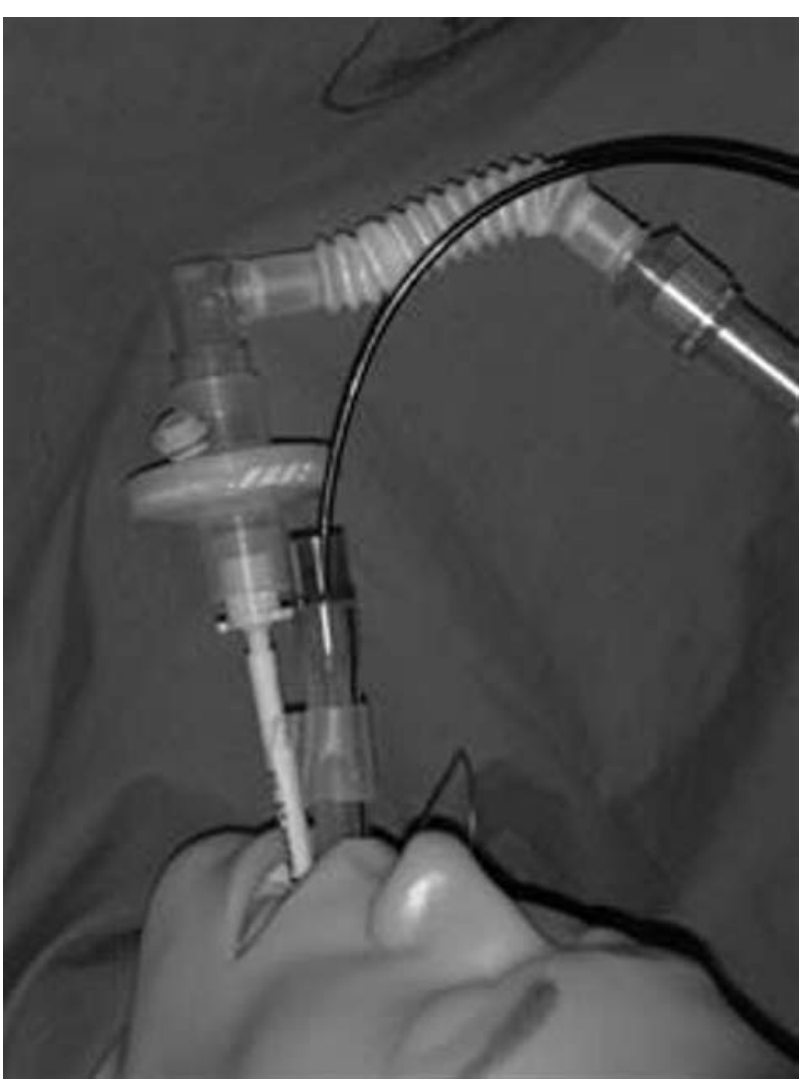

FIGURE Operating room setup with a micro laryngeal tube, laryngeal mask airway and fibreoptic scope in place.

Two further patients had preoperative recurrent laryngeal nerve palsy which persisted into the postoperative period. The first was due to tumour invasion of the nerve and, intraoperatively, the nerve was unresponsive to electrical stimulation. In the second case, the patient presented with idiopathic recurrent laryngeal nerve palsy. During the thyroidectomy for multinodular goitre the electrical stimulation demonstrated an intact nerve. Postoperatively, however, there was no improvement in nerve function.
In both these patients the technique was found to be of benefit in assuring the preservation of the contra-lateral nerve.

There was no permanent nerve palsy due to surgery in any of our 30 patients.

\section{Discussion}

With the advent of the LMA, numerous authors have described techniques to identify the recurrent laryngeal nerve during the procedure, using the LMA as the lone airway and then visualizing the larynx during electrical nerve stimulation. ${ }^{5-9}$ However, these methods all carry the inherent risk of problems with the airway intraoperatively. In one series, the anesthesiologist was required to intervene to correct the airway by tracheal intubation in $10 \%$ of cases. ${ }^{8}$ As a result, the safety of this method came into question, ${ }^{10,11}$ since correction of the airway during surgery is difficult and the loss of airway intraoperatively can put the patient at risk. With our technique, the airway is secured from the onset of anesthesia and no airway problems occurred intraoperatively. The presence of a tracheal tube did not hinder the view nor assessment of vocal cord mobility. It gave the surgeon uninterrupted operating time with the ability to stimulate electrically and trace the nerves throughout the procedure as required.

Further, the technique is suitable for all patients. Approximately $24 \%$ of our patients would have been excluded from the previously described techniques ${ }^{8,9}$ because various factors would have precluded use of the LMA as the primary airway. In these LMA-only techniques, up to $10 \%{ }^{8,9}$ of the patients were not suitable, as contraindications to the LMA existed, and there would have been no perioperative nerve monitoring. This was not a problem with our technique as the airway was protected throughout the procedure by the MLT.

The LMA provides an excellent conduit for bronchoscopic evaluation of the airway. ${ }^{12}$ It can also be used to evaluate the airway postsurgically, especially in patients in whom tracheomalacia is a concern. The removal of the MLT under deep anesthesia provides a smooth recovery from anesthesia and potentially reduces hemorrhage. ${ }^{13}$

Some techniques described necessitate the purchase of expensive monitoring and consumables, ${ }^{14,15}$ but all the equipment required for ours is familiar and available to any anesthesiologist working in a modern operating room. We believe that this is a major advantage. This familiarity and availability of equipment also allows the technique to be learnt with ease. In our experience, it increases induction time by only approximately five minutes. This can be offset by the time saved in viewing the vocal cords during anesthetic recovery. 
Recurrent nerve damage should be less than $1 \%$ for benign disease, but may exceed $2 \%$ for revision surgery and malignant disease. ${ }^{2}$ To achieve this, intraoperative nerve identification will become increasingly necessary, just as it has become indispensable during parotid surgery for facial nerve identification. The method presented has clear advantages since it allows the safe and continuous visualization of the larynx throughout the procedure while securing the airway.

\section{References}

1 Watkinson JC. Tumours of the thyroid gland. In: Jones AS, Phillips DE, Hilgers FJM (Eds.). Diseases of the Head and Neck, Nose and Throat. London: Arnold; 1998: 347-71.

2 Eisle $D W$. Complications of thyroid surgery. In: Eisle DW (Ed.). Complications in Head and Neck Surgery. St Louis: Mosby Press; 1993; 47: 423-36.

3 Sturniolo G, D'Alia C, Tonante A, et al. The recurrent laryngeal nerve related to thyroid surgery. Am J Surg 1999; 77: 485-8.

4 Mountain JC, Stewart GR, Colcock BP. The recurrent laryngeal nerve in thyroid operations. Surg Gynaecol Obstet 1971; 133: 978-80.

5 Akthar TM. Laryngeal mask airway and visualisation of vocal cords during thyroid surgery (Letter). Can J Anaesth 1991; 38: 140.

6 Tanigawa $K$, Inoue $\Upsilon$, Iwata S. Protection of recurrent laryngeal nerve during neck surgery: a new combination of neutracer, laryngeal mask airway, and fiberoptic bronchoscope (Letter). Anesthesiology 1991; 74:

966-7.

7 Greatorex RA, Denny NM. Application of the laryngeal mask airway to thyroid surgery and the preservation of the recurrent laryngeal nerve. Ann R Coll Surg Engl 1991; 73: 352-4.

8 Hobbiger HE, Allen JG, Greatorex RG, Denny NM. The laryngeal mask airway for thyroid and parathyroid surgery. Anaesthesia 1996; 51: 972-4.

9 Shah EF, Allen JG, Greatorex RA. Use of the laryngeal mask airway in thyroid and parathyroid surgery as an aid to the identification and preservation of the recurrent laryngeal nerves. Ann R Coll Surg Engl 2001; 83: 315-8.

10 Charters $P$, Cave-Bigley D. Application of the laryngeal mask airway to thyroid surgery and the preservation of the recurent nerve (Letter). Ann R Coll Surg Engl 1992; 74: 225-6.

11 Premachandra DJ, MacRae RPR. Application of the laryngeal mask airway to thyroid surgery and the preservation of the recurrent nerve (Letter). Ann R Coll Surg Engl 1992; 74: 226.

12 McNamee CJ, Meyns B, Pagliero KM. Flexible bron- choscopy via the laryngeal mask: a new technique. Thorax 1991; 46: 141-2.

13 Farling PA. Thyroid disease. Br J Anaesth 2000; 85: 15-28.

14 Eisle $D W$. Intraoperative electro physiologic monitoring of the recurrent laryngeal nerves. Laryngoscope 1996; 106: 443-9.

15 Hemmerling TM, Schmidt J, Bosert C, Jacobi KE, Klein $P$. Intraoperative monitoring of the recurrent laryngeal nerve in 151 consecutive patients undergoing thyroid surgery. Anesth Analg 2001; 93: 396-9. 